\title{
PELOS CANTOS DA CAPITAL: MIGRAÇÃO E VIDA NAS RUAS EM BRASÍLIA
}

\author{
Pedro de Andrade Calil Jabur ${ }^{1}$ \\ Cássio Henrique Oliveira da Conceição ${ }^{2}$ \\ Jussara Máximo da Silva ${ }^{3}$
}

\section{Introdução}

Este artigo é resultado de uma pesquisa realizada em 2013, como parte de um projeto acerca da população em situação de rua no Distrito Federal (DF) ${ }^{4}$. Em seu objetivo primário, este artigo visa compreender, através do contexto e das histórias de vida dos indivíduos que se encontram em situação de rua e que chegaram à região nos últimos três anos (migrantes recentes), a relação por eles construída com a cidade e seus espaços, especificamente dentro da área compreendida pelo Plano Piloto.

A situação de rua - tanto no sentido estrutural e principalmente em seus aspectos subjetivos, relacional e psíquico - será analisada aqui como forma de contextualizar a discussão a respeito da trajetória de vida desses indivíduos e tentar ampliar uma perspectiva de como as questões da situação de rua, da migração e do cotidiano desses indivíduos dentro de um espaço específico da cidade de Brasília.

Frangella (2004) observa que, ao longo das últimas três décadas, a população de rua vem sofrendo uma mudança de tratamento social e político, devido ao aumento de pessoas na rua em decorrência do agravamento da situação socioeconômica; e um gradual adensamento da teia de atendimento a essa população, abrindo espaço para sua visibilidade política e social.

Neste trabalho, visamos entender, especificamente, a situação daqueles indivíduos que, exclusivamente, tem a rua como espaço de moradia e vivência cotidiana. Girola (1998) afirma em seu trabalho que a rua possui diferentes zonas de invisibilidades mais ou menos profundas. Diferentes vivências na e da rua. Diferentes narrativas, trajetórias, situações. Ou seja, não existe uma condição ou existência de rua, também por não haver somente um tipo de rua, em seu sentido social e simbólico.

\footnotetext{
${ }^{1}$ Universidade de Brasília, Brasil.

${ }^{2}$ Universidade de Brasília, Brasil.

${ }^{3}$ Universidade de Brasília, Brasil.

${ }^{4} \mathrm{O}$ projeto de pesquisa referente foi submetido e aprovado pelo Comitê de Ética em Pesquisa em Seres Humanos da Faculdade de Saúde da Universidade de Brasília, em 10/07/2013, sob protocolo no ${ }^{\text {. }} 330.731$.
} 
É nesse sentido, portanto, que este trabalho se utilizará do termo "situação de rua", não em um sentido definitivo ou mesmo que dê conta das perspectivas conceituais e de análises expostas, mas como forma de tentar de compreender uma multiplicidade de vivências concretas e simbólicas: não é uma situação de rua, mas sim situações.

Os indivíduos em situação de rua, especialmente os que moram na rua, vivem em uma situação radical e insegura de flutuação errante dentro desse percurso social. Esta condição de sobrante social não significa, todavia, uma forma de inexistência social, mas sim de uma condição marcada por rupturas de vínculos e relações sociais concretas e simbólicas (Castel, 2003).

A condição de migrante recente, muitas vezes, parece potencializar esta situação de incerteza e precariedade. Como explica Grinberg e Grinberg (2004), para o indivíduo migrante, que se encontra (ou já se encontrava) em situação de rua, o novo espaço aonde se chega pode, dependendo das circunstâncias, funcionar como um instrumento para enfraquecer o seu mundo estabelecido até então e, por isso mesmo, sua identidade. Novos lugares, novas pessoas, relações, desemprego, misérias, memórias afetivas, podem, de certa forma, não confirmar, ou não ajudar o indivíduo estabelecer ou conectar o seu repertório individual e social a essa nova dinâmica.

A rua, referência preponderante de caracterização dessa população, além de ser um espaço de vivências, relações, sociabilidades, trabalho, moradia, é também uma condição, pois o que justamente permite designar os que a vivenciam como populações de rua é o fato de que, tendo condições de vida extremamente precárias. Ou seja, um conjunto de impossibilidades, constrangimentos e escassez a partir dos quais se desenrola todas as bases concretas e simbólicas para a construção e reconstrução de existências.

Kasper (2006) chama atenção para o perigo de uma caracterização determinista deste espaço e desta condição (e, por conseguinte, desta população) que relaciona diretamente que necessariamente uma situação de extrema pobreza gera tão somente condições materiais e sociais de subsistência. As situações na rua não podem necessariamente serem analisadas como uma vivência simplista e animalesca de luta para a sobrevivência, onde a existência, social, física e psíquica, desses indivíduos estaria limita a processos de adaptações.

A rua é um lugar de passagem, do transitório, do impessoal, ou como coloca DaMatta (1997), da competição anônima do mercado. Caminho que leva ao trabalho, ao 
lazer, ao culto e às compras. Espaço do fugaz, mas também locus de uma maneira de se construir sociabilidades. As situações de rua vividas por quem mora nelas não deixa de representar uma transferência concreta e simbólica da casa para a rua: a sala, os quartos, os banheiros - com suas respectivas as ações fisiológicas, os quartos, espaço de dormir e da sexualidade, mas também as estratégias e as relações, por vezes transitórias, por vezes não, que se formam, se criam e recriam no espaço da rua-casa. A rua, como lugar de passagem, espaço de produção de relações de sociabilidade e as interações sociais igualmente fugazes. Pessoas ou grupos de moradores de rua reproduzem, muitas vezes, papéis familiares entre os demais que compartilham o mesmo espaço, seja por pouco ou muito tempo. No mundo da rua, agrupamentos são formados usualmente de forma provisória temporal e espacialmente. Vidas, situações da e na rua.

\section{Contextualizando o espaço de Brasília}

Brasília, o espaço de chegada desse migrante, nasceu alicerçada em duas premissas básicas. Uma primeira ligada a uma utopia de se construir no interior do país uma nova capital que representasse uma nova nação, baseada principalmente no princípio de equidade entre os habitantes desse novo espaço e desse novo país e a outra relacionada ao fato de que esta cidade para se desenvolver, deveria ser, e, na realidade é, uma cidade de migrantes, um pólo de confluência de novos habitantes vindos de todas as regiões do país.

Localizar esse migrante nessa história de utopia e realidade é entender, portanto, a natureza da própria conjuntura social que esse indivíduo irá encontrar na sua chegada. Existe uma realidade concreta, bastante clara e desigual que desenha uma diferença entre a região do Plano Piloto de Brasília, compreendendo Asas Sul e Norte, Lagos Sul e Norte e os novos Setores Sudoeste e Noroeste, e suas regiões circundantes, cidadessatélite e entorno.

O Plano Piloto caracterizou-se, desde o princípio, como espaço destinado ao funcionalismo público e à classe média, enquanto as cidades-satélites foram sendo criadas em razão da migração de uma grande massa populacional em busca de empregos nas obras das empreiteiras. Os migrantes que vieram trabalhar se localizavam nos acampamentos das construtoras e os que prestavam serviços a essa população formavam vilas, próximas aos mesmos e fora do plano urbanístico idealizado, onde se 
improvisavam os serviços de apoio à construção da capital e à população aqui localizada. Os candangos, como eram chamados os trabalhadores que construíam a cidade, chegavam de caminhão de todas as regiões do país.

Por isso, antes da cidade ser inaugurada, iniciou-se o processo de erradicação das favelas e acampamentos de trabalhadores próximos ao Plano Piloto, transferindo seus habitantes para as cidades satélites. Em 1958, foi criada a primeira cidade-satélite, Taguatinga, surgida exatamente em razão da forte pressão por habitação advinda do grande fluxo migratório para a região. Posteriormente, em 1960, devido às mesmas razões, surgem outras cidades como Sobradinho e Gama. Desde a sua criação, portanto, estas cidades passaram a constituir espaços para a população excluída do planejamento da nova capital do país. Esta explosão migratória "não planejada" está consolidada nos dados da população nos primeiros anos da nova capital.

O migrante pobre, que então chegava, passou a ter como destino as cidades satélites, por isso cidades como Taguatinga, Gama e Sobradinho também receberam um fluxo considerável de população, mas diferentemente do Plano Piloto, que se formava e crescia a custa da burocracia estatal, já inseridas na lógica da cidade, essas cidades se formaram com os migrantes rurais, que buscavam na nova capital um novo horizonte de vida, uma nova forma de sonhar a própria sobrevivência. A partir deste modelo, no dizer de Paviani (1996), cria-se uma área urbana polinucleada e evidentemente diferenciada, constituída por um centro elitizado, um Plano Piloto circundado pelos demais núcleos pulverizados no território do Distrito Federal (DF). Conforme explica o autor, a partir da década de 80 , preocupado em conter o fluxo migratório de população de baixa renda para a cidade, o governo local buscou incrementar uma política de controle de migração - deixando de oferecer moradias e criar novos assentamentos na região.

Cada vez mais, portanto, o espaço de Brasília explicita concreta e socialmente uma divisão clara da sua dinâmica de afastamento da população mais pobre do centro da capital. Anteriormente, as cidades-satélites significavam justamente esse depositário da população marginalizada; atualmente o entorno da região, tanto do DF, quanto de Goiás, fazem esse papel. Na década de 1980 a 1990 a área urbana dos municípios periféricos ao Distrito Federal se expandiu extraordinariamente, pois a oferta de pequenos lotes, a baixos preços e longos prazos para pagar, fora da área demarcada do Distrito Federal, atraiu a população que pagava aluguéis nos núcleos satélites da 
Capital, enquanto as políticas locais, especificamente as relativas à área do Plano Piloto, limitavam a ação das forças de mercado.

A seletividade da ocupação das áreas do Distrito Federal empurra o migrante pobre para condições de vida precárias, e a seletividade do mercado de trabalho os leva à periferização (Nunes, 2004). O espaço de Brasília, que pretendia ser um espaço socializante e igualitário na distribuição de pessoas e atividades acabou por gerar uma estrutura explicitamente marcada pelo processo de segregação de sua população. A capital repetiu, portanto, à sua maneira, aquilo que as cidades de todas as épocas e culturas materializaram como parte integrante das mesmas: desigualdade $\mathrm{e}$ heterogeneidade, que no caso da capital se materializaram através das cidades satélites, sobretudo das grandes favelas planejadas ou dos guetos que rodeiam o Plano Piloto.

\section{As ruas impossíveis de Brasília: o caso do Plano Piloto}

O Plano Piloto de Brasília, representado pela forma de uma cruz, na concepção de Lúcio Costa, herdeiro do pensamento urbano do século XIX, corporificava e atualmente em razão de diversos fatores, concretiza, em partes a justificativa e as preocupações sanitárias e de contenção de movimentos populares do "urbanismo" do século XIX. Dentro do tipo de cidade que o modernismo condena, a rua figura como um espaço de âmbito público e que estrutura toda a vida urbana por meio da dicotomia entre público e privado, exatamente o que os urbanistas pretendiam abolir. Em Brasília, as ruas são substituídas por vias expressas e alamedas residenciais, eliminando o pedestre. Optou-se também, em todo o Plano Piloto, por eliminar a rua delineada por fachadas contínuas de prédios - a rua-corredor, facilitando assim uma maior circulação de automóveis.

\footnotetext{
A ausência da palavra 'rua' no plano é, assim, profética: revela a tentativa de desmantelar o tradicional mercado urbano, reorganizando as relações entre comércio e residência, pedestres e transporte (...). As vias de serviço em Brasília só podem ser percebidas como fitas de asfaltos atendendo às necessidades de máquinas em movimento (...) tornam-se inteiramente identificadas com as funções de transporte e abastecimento. (Holston, 1993: 143)
}

O espaço de Brasília deveria ser organizado para criar um novo tipo de relação entre pedestres e automóveis, residências e comércio. Por isso mesmo, sua unidade básica, a superquadra, é marcada por imensos espaços vazios, circundados por alamedas arborizadas. Estes espaços vazios completados por grandes edifícios deveriam ser 
também monumentos à amplitude de uma nação que buscava seu desenvolvimento. Em uma cidade onde todos os edifícios foram construídos para representar monumentos coletivos de uma nação, as superquadras, suas alamedas, as pistas de velocidade, os grandes espaços vazios, tudo se transforma em uma imensa máquina coletiva que busca integrar seus componentes de forma padronizada e hierarquizada. A monumentalidade arquitetônica do Plano Piloto, aspecto fundante na escala de concepção urbana da cidade, fortalece a ideia de confinamento dos pedestres em suas próprias áreas residenciais e comerciais. Os caminhos de pedestres na cidade, muitas vezes, não têm continuidade, sendo interrompidos pelas pistas locais, viadutos (também chamados de tesourinhas) ou acesso de veículos ao eixo rodoviário.

Além dos edifícios residenciais, a superquadra, forma de residência básica do Plano Piloto, foi planejada para ser uma unidade residencial auto-suficiente, com seus próprios serviços e equipamentos (escolas, comércio local, parques infantis). Este modelo de concepção de moraria das superquadras permite que, dentro das mesmas, sejam utilizadas, basicamente, por seus moradores e assim, pode manter-se isolada do movimento da cidade, criando espaços tranquilos em relação ao tráfico de automóveis.

\section{Relatos de vida: metodologia}

A utilização dos relatos de vida como método de investigação e instrumento de reflexão e análise por parte de historiadores, antropólogos e sociólogos, entre outros, possui uma longa tradição, inserindo-se na linha das metodologias qualitativas de investigação social, sobretudo quando é usada como técnica principal de recolhimento de dados. Dentro da tradição sociológica, como modelo metodológico, a entrevista narrativa foi elaborada pelo sociólogo alemão Fritz Schütze, no final da década de 70 se baseando principalmente na exploração de narrativas "improvisadas", isto é, relatos que o entrevistado produz sem preparação e com o mínimo de interrupção do entrevistador.

De acordo com Flick (2004), o método de análise e interpretação proposto visa, como ponto central, a reconstrução dos eventos e dos processos biográficos do narrador. O objetivo, portanto, não seria tanto reconstruir as interpretações subjetivas que o narrador elabora de sua vida, mas sim, reconstruir a inter-relação de cursos factuais de processos. 
A discussão e a prática de construir pesquisas a partir de narrativas biográficas fazem emergir uma série de discussões e aportes conceituais das ciências sociais e que, posteriormente, poderão fazer parte das próprias temáticas de análise da pesquisa. Estes aportes partem, portanto, de um arcabouço da sociologia fenomenológica, da etnometodologia e do interacionismo simbólico, no sentido de buscar justamente o entroncamento entre o individual e o social (não tomados, aqui, como polos opostos, mas inter-relacionados), o pessoal e o coletivo.

Como explica Germano (2004), o método de Schütze insere-se num panorama de revitalização dos estudos biográficos e de crescente interesse pela centralidade da narrativa, englobando não só a sociologia alemã, mas também outros autores de diferentes nacionalidades e a própria psicologia.

\begin{abstract}
A expressão narrativa da própria vida lida não apenas com eventos externos que ocorrem com o indivíduo, mas também com as mudanças internas que a pessoa deve enfrentar ao experienciar, reagir a, moldar (e até parcialmente produzir) esses eventos externos. E reconhecendo, através da narração autobiográfica, como alguém se sentiu ao experienciar os eventos externos é um primeiro passo para o indivíduo equacionar a contínua construção e transformação de seus estados internos e sua importância para a estrutura da identidade da história de vida em desenvolvimento (Germano, 2004: 4).
\end{abstract}

Nesse sentido, as narrativas construídas por permitem explicitar um conjunto de ações e pensamentos individuais contextualizadas dentro de um universo coletivo mais amplo, que à medida que são relatados se tornam progressivamente objetos de análise, mecanismos interpretativos, tanto pelo próprio sujeito da pesquisa, em nível mais individualizado, como pelo próprio pesquisador, dentro de referências sociais.

Por se tratar de uma história narrada sobre sua própria vida e uma narrativa sobre si próprio ser um elemento central de sustentação do próprio eu, a história de vida não é um instrumento metodológico que se refere unicamente a um conjunto de fatos e à relação entre eles, mas inclui também o investimento emocional do narrador. De certa maneira, contar a própria história é uma forma de reviver os eventos que se recorda e é também um ato de (re) elaboração de sentimentos, emoções e ações que lhes estão associados. Neste sentido, uma história de vida não constitui simplesmente um relato objetivo e exaustivo de eventos ocorridos na vida do narrador, nem exterior a eles, nem meramente um relato desinteressado. Pelo contrário, é um relato dotado de uma afetividade particular justamente porque é através dele que o sujeito se reconta e se 
reafirma como uma identidade tanto distinta das demais, mas com capacidade de relacionamento com as mesmas.

Por isso mesmo, as noções de identidade, de vínculos (ou relações) sociais, de memória, de tempo e de socialização se apresentam quase naturalmente no processo deste tipo de pesquisa. Necessariamente, estas referências conceituais dizem respeito a esse cruzamento entre vivências individuais e contextos sociais, quebrando, como já mencionamos esta oposição tantas vezes apresentada, ao destacar a maneira como se relaciona as instâncias individuais e coletivas, ou seja, como se forma a relação entre o indivíduo e a sociedade e de que natureza esse vínculo se estabelece dentro das mais diversas realidades.

Por isso mesmo, o relato vida se torna um instrumento utilizado para ilustrar a relação inseparável entre indivíduo e sociedade, como seu pertencimento a diferentes microcosmos sociais produzem condições favoráveis à produção de trajetórias de vida, permitindo, como explica Germano (2004), captar o que escapa às estatísticas, às regularidades objetivas dominantes e aos determinismos macrossociológicos, tornando acessível o particular, o marginal, as rupturas, os interstícios e os equívocos, elementos fundamentais da realidade social, que explicam por que é que não existe apenas reprodução, e reconhecendo, ao mesmo tempo, valor sociológico no saber individual.

Nesse sentido, estes documentos biográficos não podem nunca serem considerados reflexos passivos de uma entidade atomizada, sem envolvimento social. Como explica Pais (2009), o relato biográfico revela-se como uma prática humana e como uma espécie de síntese de uma história social. Para o autor, as narrativas biográficas se constituem em um método que acaba por atribuir à subjetividade um valor de conhecimento que constitui ponto de partida para a compreensão da realidade social.

É também a partir do espaço afetivo e simbólico, que os diversos grupos sociais podem definir suas referências e sua identidade e objetivos, determinando e organizando toda uma dinâmica de funcionamento, através do tempo, do passado, do presente e do futuro de uma comunidade. No intuito de explicitar justamente a importância desta transformação simbólica, a ideia de memória e do tempo - como instâncias constituintes de uma identidade - serve de instrumento de aproximação através da qual procuraremos entender a complexidade, simbólica e, por isso mesmo, formativa. 
Justamente, a construção de uma trajetória, de um indivíduo em situação de rua se relaciona diretamente com um complexo número de atribuições, no sentido, tanto de ser possível vivenciar perdas, rupturas, como também na possibilidade de construir, através de novos vínculos e relações, novas experiências, que de uma maneira ou de outra, ajudarão o indivíduo a viver essa nova dinâmica de vida, mas também a suportar, de uma maneira construtiva, as perdas e as possibilidades de reconstruções. Nesse sentido, o papel da memória como ponte espaço-temporal, entre essas duas novas realidades, que às vezes se apresentam de maneiras explicitamente contraditórias, é de fundamental importância.

Segundo Escorel (2000), ainda que essas narrativas revelem uma heterogeneidade de circuitos anteriores à sua situação de rua, o reconhecimento da passagem para esta se faz quase sempre a partir de histórias de perdas, que partem sempre de um acontecimento marcante que acaba gerando uma série de rompimentos: econômicos, familiares, afetivos, religiosos, entre outros. Expressões recorrentes como "de repente, virei morador de rua", "daí, acabei na rua" marcam nestas histórias a percepção de um deslocamento bruto, concreto e simbólico, para um novo contexto no qual elementos anteriores não encontram espaço, a não ser como discursos do passado.

Realizamos entrevistas com três indivíduos do sexo masculino, com idade entre 40 a 60 anos, entre junho e julho de 2013. A escolha do sexo masculino ocorreu como um passo introdutório das pesquisas, na tentativa de iniciar uma caracterização e uma primeira abordagem junto a população de rua já que - como demonstra a Pesquisa Nacional sobre a população em situação de rua (Brasil, 2008), 82\% dessa população é composta por homens.

As entrevistas foram realizadas durante o dia, prioritariamente na parte da tarde. Em média, cada entrevistado foi ouvido por cerca de duas horas em cerca de dois ou mais encontros, através de entrevistas gravadas com a anuência dos entrevistados através do Termo de Consentimento Livre e Esclarecido. Seus nomes verdadeiros foram modificados, a pedido dos próprios entrevistados.

Tendo como grande tema a questão da relação desses indivíduos com os espaços e as ruas do Plano Piloto de Brasília, a, posterior análise desta pesquisa lançará mão do próprio processo de entrevistas para tentar compreender como estes indivíduos constroem seu cotidiano (Certeau, 1990) em uma cidade que os abriga, muitas vezes, de uma forma desconhecida, violenta e apavorante. 
Recolher e analisar estas histórias se torna praticamente uma condição vital para se estabelecer um diálogo com essa população. É a partir das narrativas de suas vidas, construídas durante a pesquisa, que poderemos entender de maneira direta e indireta como se forma, concreta e simbolicamente, uma Brasília. Suas narrativas sobre a cidade, ou mais especificamente, sobre uma região da cidade, é recheada de importantes elementos analíticos sobre a condição da população em situação de rua no Brasil, sobre a condição de um migrante em uma grande cidade e sobre os sonhos coletivos (Benjamin, 1989) que formam e são formadas dentro de uma grande metrópole, por esse flaneures pobres, esfarrapados e excluídos de outras narrativas possíveis sobre Brasília.

\section{Falas da vida: uma cidade sem nomes}

Encontramos Mário deitado, debaixo de um piloti de um prédio da asa norte em Brasília. Entre dormindo e acordado, ele se assustou com nossa aproximação. Colocou a mão em suas duas sacolas plásticas, achando que íamos expulsá-lo de um espaço, que na concepção inicial da cidade, seria público, independente dos moradores do prédio. Espaço de passeio no princípio igualitário da cidade, mas por que não espaço de descanso? Estranha, quando perguntamos, se poderíamos conversar com ele.

Achei que eram moradores daqui. É o terceiro lugar que tento descansar (...) Sempre expulso. (Mário, entrevista em junho de 2013)

Mario, 45 anos, deixou a família, esposa e seis filhos, no interior do Piauí para buscar emprego em Brasília. O sonho dele era justamente poder trazer sua família para morar consigo. Depois de um período, sem emprego e sem moradia, "vivendo nas escuras" descobre que sua esposa se casou novamente e se mudou com seus filhos para um local desconhecido. Mário narra os episódios de sua vida, mas, constantemente, se refere, diretamente ou indiretamente a essa perda brusca. Uma família que ele sonhava e acreditava trazer para Brasília.

Cara, eu tô sempre perdendo. No Ceará, trabalhei de tudo até que não dava mais. Vim para cá, tentando mudar, trazer felicidade, mas aqui, eu conheci o que é perder. Não tive casa, trabalho nenhum, amigo nenhum. Tem dias que passo o dia sem abrir a boca, com uma vontade gritar e explodir. (Mário, entrevista em junho de 2013) 
Sobre sua chegada em Brasília, Mário conta, de uma maneira muito vívida, sobre o exato dia que chegou, em uma espécie de releitura, mais escura, da canção Faroeste Caboclo, do grupo Legião Urbana.

Cheguei logo de noite na rodoviária. E não tinha a menor idéia do que fazer. Andei, andei um bocadão louco, cara, debaixo de um sol. Tudo marrom de poeira. Ainda tinha uma mala, que depois levaram. Uma hora que cheguei na catedral, entrei e fiquei até fechar. Dormi ali em volta. Não conhecia nada e nem sabia de ninguém. Queria só um emprego e uma cama para deitar. (Mário, entrevista em junho de 2013)

\section{E completa,}

Aqui é tudo muito esquisito. Depois de quase dois anos, nem sei como se anda. Um monte de ruas sem nome. Na minha terra, tinha rua da Matriz, rua Doutor Manuel, rua com nome. Aqui é um monte de letra com número. Depois que perdi tudo e todos, desisti até de aprender e a gostar disso aqui. Sei andar porque vivo nos mesmos cantos. Tudo aqui pelo Norte, já que eu sou do norte, fico no norte (risos). (Mário, entrevista em junho de 2013)

A cidade vivida é transformada em um espaço de perdas, relacionais, identitária e até mesmo cognitiva. Brasília é relata por Mário, como um cenário de desmoronamento. Onde parece existir, ainda, certo fascínio, que não se desprega de suas perdas.

Aqui tem muita árvore sabe. É bonito. Às vezes, quando consigo deitar, fico pensando, olhando pro céu (...) Um bom lugar de se morrer, esse cemitério cheio de árvores, donas com cachorros, um monte de 'poderoso' e carros buzinando. Se dá para viver aqui, dá para morrer. Um cabra como eu, sem nada, bem que podia morrer aqui. Seria mais chique (risos)! (Mário, entrevista em junho de 2013)

A cidade, capital do país, sede do poder, também se embrenha em suas histórias.

Parece que só eu que tô sem documento. Todo mundo, com nome e sobrenome e documento. Eu nunca nem vou poder chegar perto daquele palácio lá do presidente. Neguinho vai chegar na porta e pedir, 'documento, por favor'. Vou falar o quê?! Ih, mais aí eu tô viajando, né?! Só quem fala com um cara desses, são esses juízes, ministro". (Mário, entrevista em junho de 2013)

Mário, explica, em outro momento, como faz 'para se virar', no dia a dia.

Aqui, é no corre corre, no esconde, esconde. Na primeira semana, eu dormindo lá, 'manezão', quando acordei, levaram tudo, até sapato (...) Para dormir, agora é sempre na mocosa, quando dá. Eu tenho lá meus esconderijos. Não gosto de ficar 
andando com ninguém não. Tem muito malandro. Isso aqui me fez só, então sou só. (...) Aproveito para ficar debaixo das árvores, eu gosto de árvores e aqui tem muita, né? (...) Tomo banho só de vez em nunca, no parque, mas é quase nunca. Para te falar, nem sei quanto tempo que eu tô nessa sujeirada toda. (Mário, entrevista em junho de 2013)

Seus esconderijos parecem algo importante valioso no dia a dia,

Todo mundo aprende a se virar. Ganho uma roupa aqui, peço um dinheiro ali e vou me ajuntando. Guardo umas roupas num 'mocó' que achei aqui perto. Muito bom. Já até pensei em colocar umas placas de zinco que juntei e chamar de casa, mas é bandeira. Na rua não se pode dar bandeira. Achei e não conto para ninguém. Só não dá para dormir, todo dia, por conta do barulho e dos ratos. Mas aquele espaço ali é meu, do Mário (enfatiza, batendo no peito). (Mário, entrevista em junho de 2013)

Na mesma hora, parece se lembrar de sua condição,

Esconderijo cheio de rato. Isso lá é lugar para se falar que é meu. É meu nada, é buraco, cheio de merda, desse lugar maluco.

Sérgio, cerca de 60 anos, estava andando pelo Eixo Monumental da cidade. Espaço feito para carros, com um descampado no centro, dividindo os sentidos da avenida. Relutante em conversar, no início, aceitou nossa proposta, quando pergunta se poderíamos lhe dar uma carona, até a rodoviária da cidade. Ao chegarmos no destino, Sérgio, pergunta se poderíamos levar na Praça dos Três Poderes, pois gostaria de conhecê-la.

Cheguei faz um pouco de tempo. Tem um ano não Tava em Tocantins, antes tava em São Paulo, Minas, Ribeirão, Sorocaba, Palestina, Florianópolis, Rio de Janeiro e Oriente Médio. Faço tudo a pé. Esse carro é de vocês? Por que, é fácil de desmontar para vender tudo e comprar passagens para a gente andar por aí. (Sérgio, entrevista em junho/julho de 2013)

A partir de uma narrativa desconexa, ele nos conta sobre suas aventuras de 'andador' por Brasília e pelo mundo, onde as cidades e as referências parecem se misturar, em um relato andarilho.

É bom de vir aqui né. Grande, só tem gente grande (...) Esse prédio com essas bacias (aponta para o Congresso Nacional), mora um gigante aí dentro né. Não posso passar perto porque 'os guardinha' tudo já me conhecem. Queria entrar para conhecer. Venho aqui todo dia, mano. Sempre andando. Hoje, que vocês pararam e fiquei de aproveitar um pouco. Andar assim, com pés de homem de ferro, às vezes enferruja. (Sérgio, entrevista em junho/julho de 2013) 
Brasília, para Sérgio, parece fazer parte de uma combinação aleatória de situações, recordações, escolhas e de sua própria condição de vida. Conhece todas as cidades, mas não se vincula a nenhuma, assim como afirma conhecer todos por onde passa, mas não se relaciona a ninguém.

Aqui é tudo grande, tudo imenso, tudo cheio de gente, caminhando nos ônibus, nos trens, nas ruas, nas avenidas, nas praças. Essa cidade parece o mundo, parece o Oriente Médio (...) Muita gente bonita, bonita mesmo. Em pouco tempo, já conheci todo mundo aqui, porque sei falar muitas línguas, Então fica fácil para mim. (Sérgio, entrevista em junho/julho de 2013)

Mesmo, através de uma geografia muito própria, transparente do seu mundo social e interno, Sérgio parece se impressionar com uma certa monumentalidade de Brasília e de relacioná-la com sua condição.

É bom de conhecer essa capital do país. É a oitava capital do Brasil que conheço. Não sei quantas capitais centrais o Brasil tem, mas essa e a mais capital de todas. Capital assim com letra maiúscula. Cheia de gente de terno, gravata, carro, celular. (...) $\mathrm{O}$ mais bonito aqui são esses prédios de gigante, com esse gramadão aí no meio. Eu conheço mais cidades que vocês, posso dizer isso com autoridade: aqui é terra para gigantes. Não é para anãozinho, não. Anãozinho que nem eu, fica aqui chupando dedo querendo entrar nos prédios para conhecer. (Sérgio, entrevista em junho/julho de 2013)

Tentando buscar, outros aspectos da cidade em nossa conversa, Sérgio conta um pouco da sua história e do seu dia a dia em Brasília.

Eu tô aqui de passagem, mas já deu para entender a cidade. É como outras, corre corre daqui, corre corre de lá, um monte de gente indo trabalhar de um lado para o outro e a noite, de noite mesmo, sobra só os vagabundos e o sem casa, como eu. Por opção, viu. Sem casa por opção. Tenho família, documentos e tudo. Só estou nessa, porque meu trampo é esse: andar, ando, chego, me amoito, conheço gente e vou-me embora. Arrumei um canto para dormir, para pedir comida e tomar banho (porque eu não sou como esses vagabundos fedorentos, não), eu tô safo. Aqui perto tem umas bicas de torneiras, onde dá para tomar um banho de noite, cagar, pegar água para beber, para cozinhar (...) E depois fica fácil encontrar nessas quebradas cheios de prédios baixos, umas árvores para montar e dormir em cima (...) Sou igual o homem aranha, mano. Aprendi dormir em cima das árvores. Sei só de olhar qual presta e qual não presta para dormir. (Sérgio, entrevista em junho/julho de 2013)

$\mathrm{Na}$ segunda vez que encontramos Sérgio, depois de combinarmos um novo encontro, ele estava ao pé de uma árvore, que nos indicou, dentro do parque da cidade. 
Nesta segunda conversa, ele demonstra, com uma fala mais pausada, uma maior clareza, pelos menos em alguns aspectos sobre sua relação com a cidade.

Sabe que tô gostando disso aqui. Aqui é calmo, ontem nem fui nos poderes (referese à Praça dos Três Poderes). Fiquei ouvindo os passarinhos. Acho que vou ficando um pouco mais (...) Gosto de passear por aí até cansar, mas aqui está muito bom. Cidade de gente grande, mas tem um céu muito grande (...) Isso o horizonte, parece um céu grande esta cidade. (Sérgio, entrevista em junho/julho de 2013)

Talvez por isso, Sérgio consegue apontar, de uma maneira mais concreta, sua (ainda) pouca relação com Brasília.

O mais difícil é arrumar comida. Passei nuns bares e nada de ninguém arrumar um arroizinho com feijão pro negão aqui. Povo meio de cara feia, sabe. (Sérgio, entrevista em junho/julho de 2013)

Encontramos Paulo, 55 anos, acampado debaixo de uma árvore perto do centro de Brasília. Muito receptivo e bastante eloquente, ele se apresentou como advogado e historiador. Veio para Brasília, há cerca de dois anos, depois de morar na rua em São Paulo, onde perdeu o emprego por causa "das farras com bebida e pó". Segundo ele, desistiu de procurar emprego e resolveu viver na rua, onde pode "parar para pensar melhor".

Eu sou muito doido cara. Não tem dessa não, bebo, cheiro, só não me meto com pedra (crack) porque aí é o fim dos tempos, entrada pro inferno zumbi, Prefiro ficar na minha mesmo e como não jeito de ficar na sua e bater ponto todo dia, dizer amém para patrão e engravatado e sebento a rua me deu essa liberdade. (Paulo, entrevista em agosto de 2013)

Dentro da cabana montada, Paulo possui um fogão, livros e revistas velhas e sacos plásticos, contendo um monte de roupas e cadernos, que segundo ele, faz parte do livro que está escrevendo. Ao ser questionado, se vive ali, naquele local, há bastante tempo, ele frisa o caráter errante da vida nas ruas.

Na rua não tem muito dessa de vivo aqui ou vivo ali, endereço para correio, não (risos). Hoje eu tô aqui. Hoje, não, essa semana. A coisa vai ficando preta, chega polícia, ou malandro querendo abrigo, ou ficar aqui 'enchendo o saco', eu pego minhas coisas e saio fora. Então hoje eu estou aqui, amanhã, não sei, depois, também não sei. Depois eu volto, depois eu vou. Não estou esperando nenhuma carta mesmo (...) então meu negócio é esse, recolho a parafernália e tchau e benção. (Paulo, entrevista em agosto de 2013) 
Com um tom sempre bastante enfático e discursivo e, por vezes, repetitivo, Paulo demora a nos contar sobre sua experiência em Brasília e suas razões de ter escolhido ficar na cidade.

Aqui é tudo na paz. Inferno mesmo é São Paulo, cara. Aí o bicho pega, cheio de nóia, policial, madame com cachorro, todo mundo querendo rancar o coro de cada um. Aqui é na paz. Brasília é na paz (...) na paz naquelas, porque também tem nóia, polícia e madame com cachorro, mas aqui dá para parar e ficar matando uns 'gorós' e ficar pensando na vida. Você vê, quando é que poderia armar barraca nesse gramadão em São Paulo. Não tem nem grama lá cara. Então eu vim para cá, ficar de boa, escrever, pensar, refletir. É uma boa cidade para refletir. Aqui só não reflete quem não tem tempo e eu tenho todo o tempo do mundo. (Paulo, entrevista em agosto de 2013)

Sobre o dia a dia, Paulo relata alguns aspectos da cidade e do seu cotidiano,

A rua é a rua, a rua ensina mais do que acordar cedo, tomar banho, colocar terno, pegar busão e ir trabalhar. Aprendi a me virar na rua, com um que vem e ensina jeito de cozinhar, ou onde tem comida. Depois você encontra um canto prá cagar, prá tomar banho, prá dormir. Aqui é fácil de arrumar as coisas, o problema é que é tudo longe prá caralho, então tem que ter perna e fígado de elefante para andar, andar, andar (Paulo, entrevista em agosto de 2013)

Dia desses, eu estava procurando no lixo, alguma coisa para comer, ali na quadra comercial de cima, e veio um sujeito querendo saber porque eu estava mexendo no lixo dele. Eu fiquei quieto, mas lixo tem dono? Achei engraçado, me deu vontade de falar pro cara, 'se é teu leva prá casa, trouxa!' Mas fiquei na minha. Por isso, que meu dia á trocado, prefiro ficar acordado de noite, saio lá pelas 6 horas para caçar comida, quando está todo mundo de cabeça quente para voltar para casa e não tem ninguém para reclamar propriedade de lixo. (Paulo, entrevista em agosto de 2013)

Brasília, em sua eloquência discursiva, parece representar um espaço de fuga constante, onde ele tenta lutar para garantir o que ele chama de paz e sossego, construindo formas efêmeras de sociabilidade, que ele acaba relacionando com os aspectos da própria cidade.

Eu tento ficar na minha, tento ficar quieto para não chamar atenção dos robôs vigilantes dos bons costumes. Isso aqui tem mais do que em São Paulo, neguinho que vem e crítica e acha ruim que você está perto da loja, debaixo de prédio, pegando água, acampado. Aí, deu na telha, encho o saco, eu saio fora. Tô querendo meu sossego, não estou querendo arrumar treta com ninguém daqui não. Acho lindo esse céu azul, que não chove nunca, cheio de mato, moita. Dá para es esconder, dá para cagar, trepar. De vez em quando dá para arrumar umas namoradinhas aqui na rua, mas tudo muita doida, tão afim é de arrumar uns 5 conto para comprar pedra (...) Aí na necessidade a gente paga (...) Então é assim, aqui todo mundo é carro, eu também sou carro, essas minas também, porque está todo mundo com pressa: para transar, para fumar pedra, para trabalhar, para comer, para ficar junto, para não ficar, para dormir (...) Corrida contra o tempo. É por isso, que preciso de me sossegar 
disso cara, me esconder nos meus cantinhos, se não enlouquece 'brabamente'. (Paulo, entrevista em agosto de 2013)

Ao insistirmos sobre a troca que ele faz do dia com a noite, em nosso terceiro encontro, ainda no mesmo local, Paulo relata um pouco mais sobre esta Brasília de cantos e esconderijos.

\begin{abstract}
Tem que ser no escuro, cara. Nós somos tudo escuro, quem mora na rua é escuro de nascença ou de sujeira da vida, de pobreza e de ser esculachado. Mas a gente se acostuma a viver na noite para não ser roubado, queimado, estuprado. Aí é o sossego, ninguém na rua, poucos carros, as luzes dos prédios vão apagando uma a uma, gosto de ficar olhando, imaginando quem está dormindo, quem está transando, vendo televisão. Eu aqui de fora, consigo curtir essas avenidonas, sem barulho na cabeça, sem corre corre (...) passeio por um lado, por outro, quando tenho grana compro umas biritas, arrumo pó, saio por aí com a barraca nas costas, na mochila (...) sim, aí a cidade fica bonita, porque fica mais calma (...) Toda calma é bonita, já dizia o advogado e historiador Paulo. Brasília é bonita de noite, de dia, na rua é igual todas as outras. (Paulo, entrevista em agosto de 2013)
\end{abstract}

Paulo afirma, em nosso último encontro, que gosta da cidade e não tem vontade de ir embora. Minimamente, conta-nos um pouco sobre sua família e sobre sua vida.

Daqui eu gostei sim. Minha mãe sempre me falou que eu era um menino ansioso, inquieto. Mas sempre fui muito inteligente. Só que não sabia disso, era meu pai, que se mandou logo quando nasci. Cresci e tive estudo, cara. Só que não é a minha não, ficar trabalhando, trabalhando. Não casei por isso, depois minha mãe morreu e fiquei só Então cara é isso (...) Não gosto de praia, não gosto de montanha, não gosto de fazenda, pouco gosto de gente, ser humano. Aqui não tem montanha, não tem praia, não é fazenda, então aqui fiquei. Também quase não tem gente, ninguém tem olho para ficar te olhando, nem ouvido para escutar e nem boca para ficar trocando idéia com vagabundo, então, meu chapa, aqui estou, aqui eu fico. (Paulo, entrevista em agosto de 2013)

Ao tentarmos entender, um pouco mais das razões dessa escolha, Paulo continua,

Vocês ficam me perguntando sobre estar aqui. Não sei se é aqui mesmo, Brasília, com todas essas letras. Deve ter lugar melhor que esse, com certeza, mas sabe o que me deixou ficando: a paz, o sossego e o céu. Eu gosto e não gosto disso aqui, dezze vazio, mas eu acho que me faz bem e enquanto me fizer bem, cá estou, sem lenço, sem documento e com as barracas nas costas, as sacolas nas mãos. (Paulo, entrevista em agosto de 2013)

\title{
A cidade vista pelas ruas da migração: considerações finais
}

As trajetórias de vida que buscamos aqui apresentar são marcadas substancialmente por histórias de rupturas, por vínculos desfeitos; por um sentido, de 
pertencimento e construção de sua própria sociabilidade, interrompido por mudanças, desaparecimentos, demissões, estranhamentos. Nesse sentido, as particularidades das experiências narradas e a forma como cada indivíduo reage dentro de sua trajetória de vida na rua e se relaciona, portanto, com os espaços da cidade, não nos permite construir generalizações teóricas, mas não impede uma análise crítica a partir dessas novas e outras construções sociais e simbólicas a respeito da cidade.

Michel de Certeau (1990) destaca uma forma de vivenciar a cidade, a partir da sua experimentação cotidiana. Se existe uma visão do espaço urbano que o observa de cima, através de mapas e planificações (técnica-urbanística), existe uma perspectiva de baixo, de dentro, a partir do dia a dia ordinário de uma cidade, que também é possível de construir narrativas.

O espaço, nesse sentido, é um lugar praticado, ou seja, um cruzamento de forças motrizes, que geram movimento e animação ao lugar; uma estrutura marcada simbólica e historicamente. Por isso mesmo, a cidade pode ser considerada um conjunto de espaços sobrecarregados de sentidos construídos, exatamente, por seus usuárioshabitantes, abrindo a possibilidade de se buscar nos seus ícones e signos expostos, uma maneira de ler suas representações e reconstruções, como um lugar onde os discursos de uma sociedade deixam-se ler nos signos expostos.

A nova capital, cidade tecnocraticamente planejada pelo Estado desenvolvimentista da década de 1960, nasceu como monumento a um futuro através de várias narrativas já previamente instituídas. Brasília não nasce de um gesto coletivo espontâneo de homens e mulheres, mas a partir de traços urbanísticos, arquitetônicos, econômicos e geopolíticos. A partir de uma arquitetura neutra, monumental, definida pelas expressões de escala, harmonia e disciplina espacial e social, Brasília seria a representação concreta de um mito de fundação de uma nova sociedade e um novo país, onde as narrativas de um futuro grandioso para a cidade e para o país se confundem de forma proposital.

Nesse sentido, observar como são criadas essas outras narrativas de baixo no próprio desenvolvimento de uma cidade ainda nova é um dos pontos de partida desses relatos apresentados.

Manuel Delgado (2007) afirma que a rua, nas grandes cidades é o ponto principal da fluidez movediça da vida urbana. Fluidez que, no dia a dia, é capaz de criar novos e outros sentidos para os espaços planejados e instituídos de uma cidade. Os praticantes 
das cidades, seus cidadãos, segundo o sociólogo espanhol, através da prática desses espaços, são capazes de atualizar e reescreverem a história da cidade, dos seus projetos urbanos e do próprio urbanismo.

Ao entrarmos em contato com esses indivíduos em situação de rua, pode-se perceber um outro tipo de narrativa, um outro ritmo da e na rua que é marcado por uma temporalidade e por condições de existência e sobrevivência no dia a dia outras. Virações de sobrevivência, corpos errantes, corpos estáticos e extáticos, esses muitas vezes mergulhados em virações de como viver o dia a dia no desconhecido espacial e social. É nesse sentido que a migração, no desenvolvimento e no sentido dessa pesquisa não é somente a mudança em si para Brasília, mas é a própria condição, real e metafórica, da qualidade da trajetória desses indivíduos a partir dos usos e impedimentos que fazem e encontram nas teias do Plano Piloto de Brasília.

Espaços e ruas planejados que se tornam cantos, esconderijos, objetos de admiração, incertezas, medos. Figuração das situações de pobreza, miséria, solidão, que se assemelham às características do homem lento, personagem elaborada por Milton Santos (1996), ao se referir ao homem comum, em sua maioria, pobre, que, no ambiente das metrópoles globalizadas não têm acesso a velocidade e a aceleração concreta e simbólica do mundo contemporâneo. Aqueles que vivem, moram, comem, tomam ou não banho, fazem suas necessidades na rua possuem em sua condição este aspecto apresentado pelo geografo brasileiro de lentidão.

Como relata Mário acerca das impressões vividas por ele, em Brasília,

A gente tenta se esconder para não ser incomodado (...) E parece então que vivo procurando esses cantos, escondidos (...) Viver na rua, cara, é viver no escuro, não tem essa de ficar aparecendo muito não. Se eu ficar aqui todo aparecido, andando de um lado por outro, sujo, logo alguém chega: polícia, porteiro de prédio, segurança de loja, mandando sair, dando baculejo (...) Aqui ou você corre, ou você se esconde. Eu já tenho idade para passar a vida correndo de polícia não. Por isso me escondo. (Mário, entrevista em junho de 2013)

Narrativas sobre a cidade que se confundem com os próprios relatos de vida desses moradores; onde o canto marginalizado e estigmatizado parece ser, um dos possíveis retratos, daqueles vivem nas ruas das grandes cidades brasileira. Os espaços da cidade, para esses moradores recentes, se tornam cantos, esconderijos, lugares para se construir uma vida. 
Eu não escondo nada não, mas como é que fico andando assim por aí. Você vai pedir um copo de água em um bar ou abre a torneira debaixo de um prédio, tem sempre alguém para falar que não pode, ou te ameaçar. Beber água, cara. Água tem em tudo quanto é lugar, mas para nós não tem não. Tem que ser escondido (...) tudo tem que ser nas quebradas, se não 'nego' vem e te quebra de porrada, de xingamento, leva tuas coisas, coloca fogo, chama de vagabundo. Sou vagabundo, não. Sou da rua, porque não tenho casa, então vou mesmo é ficar na moita. (Paulo, entrevista em agosto de 2013)

Le Blanc (2007) ao refletir sobre a trajetória dos indivíduos da rua, define a questão da ausência da voz como um ponto de inflexão que caracteriza uma situação de precariedade. A ausência não se daria pela inexistência da voz e das palavras, mas sim pela falta de um espaço onde essas vozes poderiam ser ouvidas, ou mesmo, por não haver um outro para escutá-las.

Ao conversamos com Paulo sobre a forma como ele se localiza no Plano Piloto, ele nos esclarece sobre esta solidão vivida e convivida na cidade.

\begin{abstract}
Aqui tudo é muito doído e doido, ao mesmo tempo. De vez em quando até chega uns cara aqui, a gente toma umas, conversa, troca umas idéias. Mas parceria mesmo, não tem não. Eu vejo mais carro, ônibus e caminhão passando por aqui, do que gente. Gente, gente mesmo prá conversar, namorar, tem não cara. É cidade de máquina com um monte de gente apressada que não para prá ouvir, nem trabalhador, o que dirá, indigente que nem eu. É tudo um ‘vaziozão' horroroso, aí você anda e encontra outro vazio e depois outro vazio. Aí depois tem uma avenida enorme que não tem como passar, viaduto para escalar (...) Aqui de pé, só sendo maluco ou ferrado na vida que se vive. (Paulo, entrevista em agosto de 2013)
\end{abstract}

A voz, nesta pesquisa, poderia ser representada pelos próprios espaços utilizados por esses indivíduos. Espaços sem nome, sem posse, sem outros para compartilhar, a Brasília desses indivíduos é vivida de maneira insegura e transitória, que parece não ecoar os sentidos construídos por esses indivíduos. A falta de resposta, acolhimento é tangível nos relatos. A cidade, espaço feminino do abrigo, se torna um lugar sempre efêmero, cheio de intempéries, lugar de esconderijos e cantos sem nome.

\title{
Referências
}

BENTO, António; BARRETO, Elias. Sem Amor Sem-Abrigo. Lisboa: CLIMEPSI, 2002.

BERGER, Peter \& LUCKMANN, Thomas. A construção social da realidade. $5^{\circ}$ ed. Petrópolis: Editora Vozes, 1983. 
BRASIL. Pesquisa Nacional sobre a população em situação de rua. Sumário Executivo. Governo Federal, Ministério do Desenvolvimento Social e Combate à Fome, Brasília- DF, 2008.

BENJAMIN, W. Obras Escolhidas, v. III, Chrales Baudelaire, um lírico no auge do capitalismo. São Paulo: Brasiliense, 1989.

CASTEL, Robert. As metamorfoses da questão social (Uma crônica do salário). $4^{\circ} \mathrm{ed}$. Petrópolis: Vozes, 2003.

DAMATTA, Roberto. A Casa e a Rua. Espaço Cidadania, Mulher e morte no Brasil. $5^{\text {a }}$ edição. Rio de Janeiro - 1997

DELGADO, M. Sociedades movedizas: pasos hacia una antropología de las calles. Barcelona: Anagrama, 2007.

ESCOREL, S. Vidas ao leú. Rio de Janeiro: Fiocruz, 2000.

FERRAROTI, F. Histoire et histoires de vie. La méthode biographie dans les sciences sociales. Paris, Librarie des Méridiens, 1983.

FLICK, U. Uma introdução à pesquisa qualitativa. Porto Alegre: Artmed/Bookman, 2004.

FRANGELlA, Simone Miziara. Corpos Urbanos Errantes: Uma Etnografia da Corporalidade de Moradores de Rua em São Paulo. Tese de Doutorado em Ciências Sociais apresentada ao Departamento de Antropologia do Instituto de Filosofia e Ciências Humanas da Universidade Estadual de Campinas, 2004.

GERMANO, Idilva Maria Pires. Aplicações e implicações do método biográfico de Fritz Schütze em Psicologia Social. Arquivos Brasileiros de Psicologia. 60 (03).

Disponível em http://www.psicologia.ufrj.br/abp/, 2004.

GIROLA, Claudia M. Recontrer des personnes sans abri. Une anthropologie réflexive. In: Politix. Vol. 9, n 34. Deuxième trimestre, p: 87-98, 1998.

GRINBERG, León \& GRINBERG, Rebeca. Migração e Exílio: estudo psicanalítico. Lisboa, Portugal: Climepsi Editores, 2004.

HOLSTON, James. A Cidade Modernista: uma crítica de Brasília e sua utopia. SP: Companhia das Letras, 1993.

KASPER, Christian Pierre. Habitar a rua. Tese de Doutorado apresentada ao programa de Doutorado em Ciências Sociais do Instituto de Filosofia e Ciências Humanas da Universidade Estadual de Campinas, 2006.

LE BLANC, G. Vidas ordinárias Vidas precárias: Sobre la exclusión social. Buenos Aires: Nova Visión, 2007.

NUNES, Brasilmar F. Brasília: A fantasia corporificada. Brasília: Paralelo 15, 2004.

PAIS, José Machado. Nos rastos da solidão: deambulações sociológicas. Lisboa: Ambar, 2006. 
Sociologia da vida cotidiana - Teorias, métodos e estudos de caso. $4^{\circ}$ edição. Lisboa: ICS, 2009.

PAVIANI, A. (Org.). Brasília: moradia e exclusão. Brasília: Ed.UnB, Coleção Brasília, 1996.

SANTOS, Milton. A natureza do espaço: técnica e tempo, razão e emoção. São Paulo: Hucitec, 1996

Recebido em:29/09/2014

Aprovado em: 11/11/2014 